\title{
BEHAVIORAL INTERACTIONS BETWEEN OPIATE AND ANTIEPILEPTIC DRUGS IN THE MOUSE
}

\author{
R. J. KatZ and K. Schmaltz \\ Mental Health Research Institute, Department of Psychiatry, University of Michigan \\ Medical Center, Ann Arbor, MI 48109, U.S.A.
}

(Accepted 22 September 1980)

\begin{abstract}
Summary-Morphine and related opioid compounds are known to possess proconvulsant activity based upon both electroencephalographic and behavioral criteria. The present authors previously suggested that opiate-related seizures were behaviorally inhibitory, and this was further investigated in the present study. The effects of pretreatment with three pharmacologically distinct compounds (sodium valproic acid, trimethadione, taurine) upon normal behavioral activation to systemic morphine were examined in the mouse. Morphine consistently increased activity levels in comparison with vehicle. Each of the three experimental compounds itself was behaviorally inhibitory; nonetheless both sodium valproate and trimethadione facilitated behavioral responses to morphine. The effects of the same drugs upon activation produced by central administration of a long-lasting enkephalin analog (D-ala ${ }^{2}$-leu-enkephalina* mide) were investigated, with similar results. These findings confirm a behavioral interaction between opiate and anticonvulsant drugs, although it may be selective for certain classes of anticonvulsant compounds.
\end{abstract}

Previous studies (Cookson and Mann, 1978; Katz and Schmaltz, 1979) have proposed the existence of behavioral interactions between endogenous and exogenous opiates and anticonvulsant drugs, with anticonvulsants facilitating behavioral activation to opiates. It may be inferred that some property of opiates, possibly related to seizures, normally inhibits at least certain classes of behavior and this additionally supported electroencephalographically (e.g. Urca, Frenk, Liebeskind and Taylor, 1977; Tortella, Moreton and Khazan, 1978). To date, only a limited number of anticonvulsants have been evaluated for their effects upon opiates, either behaviorally or electroencephalographically. Given the range of anticonvulsant drugs with both related and distinctive modes of action, the generality of effects across drug categories might merit additional examination and comment.

To investigate the presence and generality of previously reported behavioral interactions, opiate and opioid running after pretreatment with a variety of anticonvulsant drugs was examined. In particular, the pharmacologically distinct anticonvulsants, sodium valproate, trimethadione and taurine were examined for their effects upon behavioral activation induced either by systemic morphine or by central injection of a long-lasting enkephalin analog (D-ala ${ }^{2}$ leu-enkephalinamide).

Examination of enkephalin analogs may shed further light upon the reported behavioral effects. The

Key words: activity, enkephalin, morphine, valproic acid, taurine, trimethadione. use of analogs allows examination of the generality of the reported interaction across opioid classes and may enable further specification of the mechanisms underlying their effects. For example, one possible explanation of results based upon systemic opiate administration is essentially pharmacokinetic in nature. The behaviorally effective anticonvulsants may have affected morphine disposition in a manner permitting altered tissue levels, including brain levels, thereby producing a changed behavioral effect. Such effects are ruled out in the present design since enkephalin injections were central, standardized and directed to a single tissue, thereby eliminating effects due to altered disposition across tissues.

\section{METHODS}

\section{Subjects}

Adult male Swiss-Webster mice, $30-35 \mathrm{~g}$ each, were group housed with food (Teklad $4.0 \%$ fat rodent diet S-0836) and tap water continuously available and a $12 \mathrm{hr} / 12 \mathrm{hr}$ light-dark cycle (lights on $=0700-1900$ ). Cell sample sizes for the first experiment (based upon systemic morphine) were $n=36$, run as 9 cells of grouped mice $(n=4 /$ cage) per data point. In the experiment involving central enkephalin injections, each data point was based upon 5 mice, run individually. The use of grouped mice in assessing morphine effects upon activity is a standard procedure in this and other laboratories (e.g. Katz and Schmaltz, 1979).

\section{Surgery}

For the enkephalin injections, mice were anesthe- 
tized with sodium pentobarbital (Nembutal $50 \mathrm{mg} / \mathrm{kg}$, i.p.) and stereotaxically implanted with permanently indwelling 23 gauge stainless-steel cannulae as previously described (Katz, Carroll and Baldrighi, 1978). Each cannula was located in the lateral cerebral ventricle, based upon coordinates of $-2.2,-1.0$, $-2.2 \mathrm{~mm}$ posterior, lateral and dorsal from the Bregma suture. One week was routinely allowed for recovery from surgery.

\section{Apparatus}

Testing apparatus and sensitivity settings were essentially similar to previous reports (Katz and Schmaltz, 1979). In brief, activity was measured upon four commercially available tuned oscillators operating upon a capacitance sensing principle (Stoelting, Chicago). Monitors were initially calibrated to within $5 \%$ of each other by measuring the activity of a single group of morphine $(50 \mathrm{mg} / \mathrm{kg})$-injected mice and adjusting to a common score at $30 \mathrm{~min}$ post-injection. Final values were calibrated based upon detector levels of 20 and an intermediate (i.e. $\mathrm{N}$ ) level trigger reset function. Mice were tested as individuals or groups in $51 \times 41 \times 22 \mathrm{~cm}$ polypropylene cages (Scientific Products Series 70) placed directly upon the sensing devices. A bedding of fresh pine chips was placed in each cage prior to the introduction of the subject. Additional details of apparatus and procedure are available in Katz et al. (1978) and Katz and Schmaltz (1979).

\section{Behavioral procedure}

Grouped or individual for enkephalin injections, the mice were initially habituated to apparatus placement and injection $(0.9 \%$ sodium chloride, $10 \mathrm{ml} / \mathrm{kg})$ procedures in 8 sessions each of 4-6 hr duration. On the test day, subjects were placed on the apparatus beginning at $0800-0900 \mathrm{hr}$. Five hours were allowed for further and final habituation before testing, at which point subjects were briefly removed and injected with vehicle or anticonvulsant. Thirty minutes later mice were injected with vehicle or opiate. Experimental recording continued for ten consecutive 10 min blocks.

\section{Drugs}

Morphine sulfate was injected intraperitoneally $50 \mathrm{mg} / \mathrm{kg}$. D-Ala ${ }^{2}$-leu-enkephalinamide (prepared fresh or stored at $4^{\circ} \mathrm{C}$ for less than $24 \mathrm{hr}$ in polypropylene containers) was injected 12.5 or $25 \mu \mathrm{g} /$ mouse in $5 \mu \mathrm{l}$ of $0.9 \%$ sodium chloride solution. Central injections were administered manually via a Hamilton microsyringe with infusion times of less than $30 \mathrm{sec}$. Trimethadione (Abbott) 0,50 or $100 \mathrm{mg} / \mathrm{kg}$ was administered dissolved in $0.9 \%$ sodium chloride vehicle. Sodium valproic acid (Abbott) 0, 12.5 or $25 \mathrm{mg} / \mathrm{kg}$ was administered sonified and freshly suspended in saline vehicle. Taurine (2-aminoethanesulfonic acid; Sigma T-0625) was administered 0, 2, 20 or $200 \mathrm{mg} / \mathrm{kg}$ dissolved in vehicle.

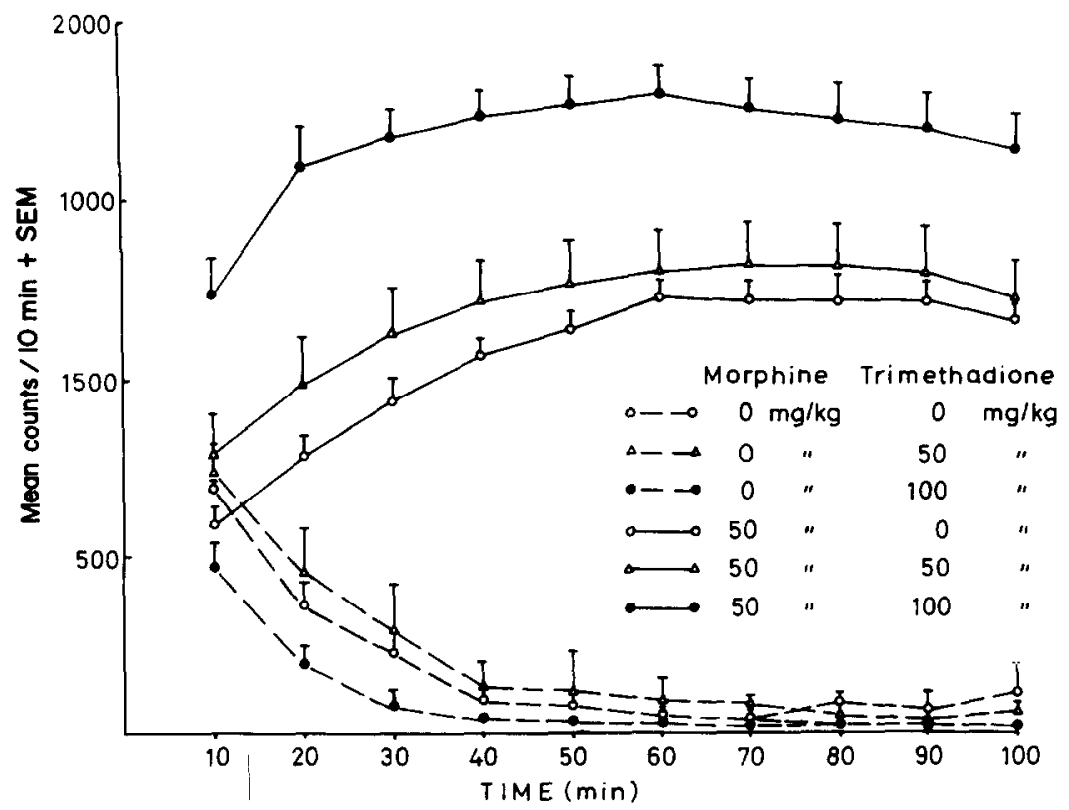

Fig. 1. Behavioral interactions between morphine sulfate and trimethadione in grouped mice data presented as means and standard errors, based upon 9 determinations per data point. Broken lines represent animals which did not receive morphine, while solid lines represent those which did (as $50 \mathrm{mg} / \mathrm{kg}$. i.p.); open circles, triangles and solid circles respectively are 0,50 and $100 \mathrm{mg} / \mathrm{kg}$ of trimethadione administered $30 \mathrm{~min}$ prior to morphine or vehicle. Extensive $(5 \mathrm{hr})$ habituation immediately preceded testing. Recording was based upon a remote sensing device beneath the cage as described in the 


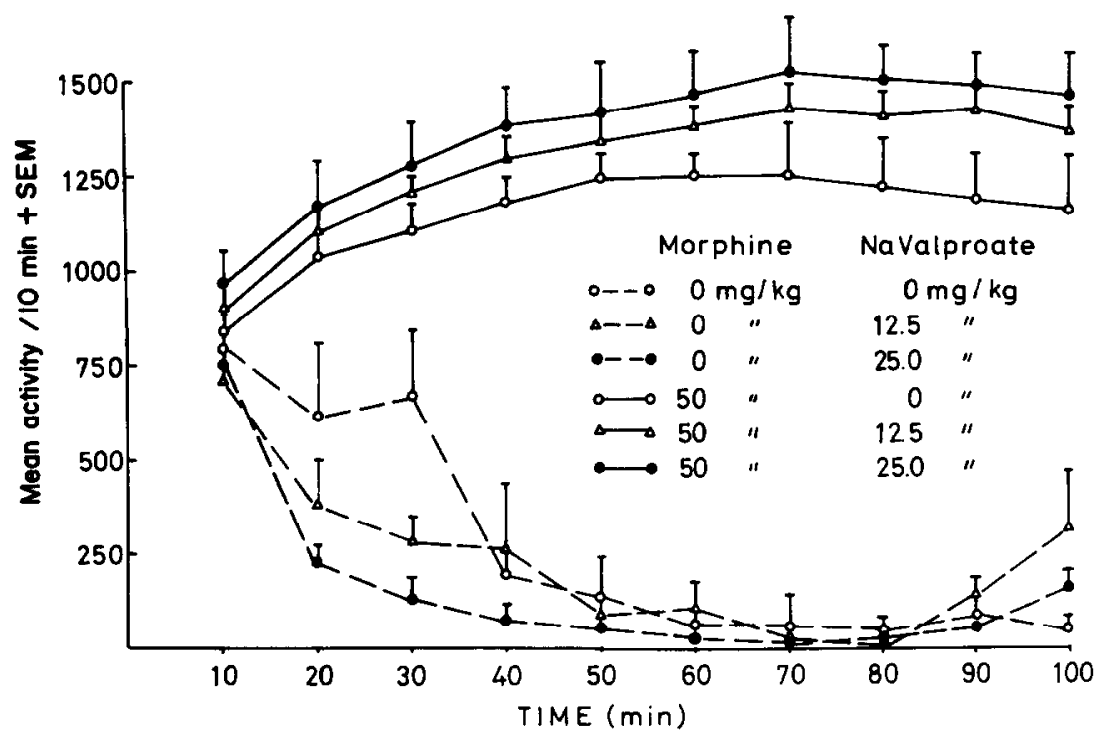

Fig. 2. Interactions between morphine and sodium valproate in grouped mice. Motor activity is displayed as means and standard errors based upon 9 determinations per data point. Broken lines represent groups not receiving morphine while solid lines received morphine $50 \mathrm{mg} / \mathrm{kg}$. Open circles, triangles and solid circles represent $0,12.5$ and $25 \mathrm{mg} / \mathrm{kg}$ of sodium valproate injected $30 \mathrm{~min}$ prior to morphine or vehicle. Extensive $(5 \mathrm{hr})$ habituation immediately preceded testing. Recording was based upon a remote sensing device beneath the cage as described in the text.

\section{Statistical analysis}

All data are presented as means and standard errors of the mean. Further analyses involved 3factor analyses of variance. The factors were: presence vs absence of morphine, presence vs absence of anticonvulsants, and time ( $\min 0-100$ ), with repeated measures upon time). Due to an initial lack of homogeneity in variance across cells, it was felt desirable to transform scores prior to analysis. The trans- formation $Y_{i}=\left(X_{i}+1\right)^{1 / 2}$ was therefore routinely employed. More detailed rationale for this particular transformation is provided in Dixon and Massey (1969).

\section{RESULTS}

Three anticonvulsant drugs were examined for their effects upon normal and opiate-elicited activation in

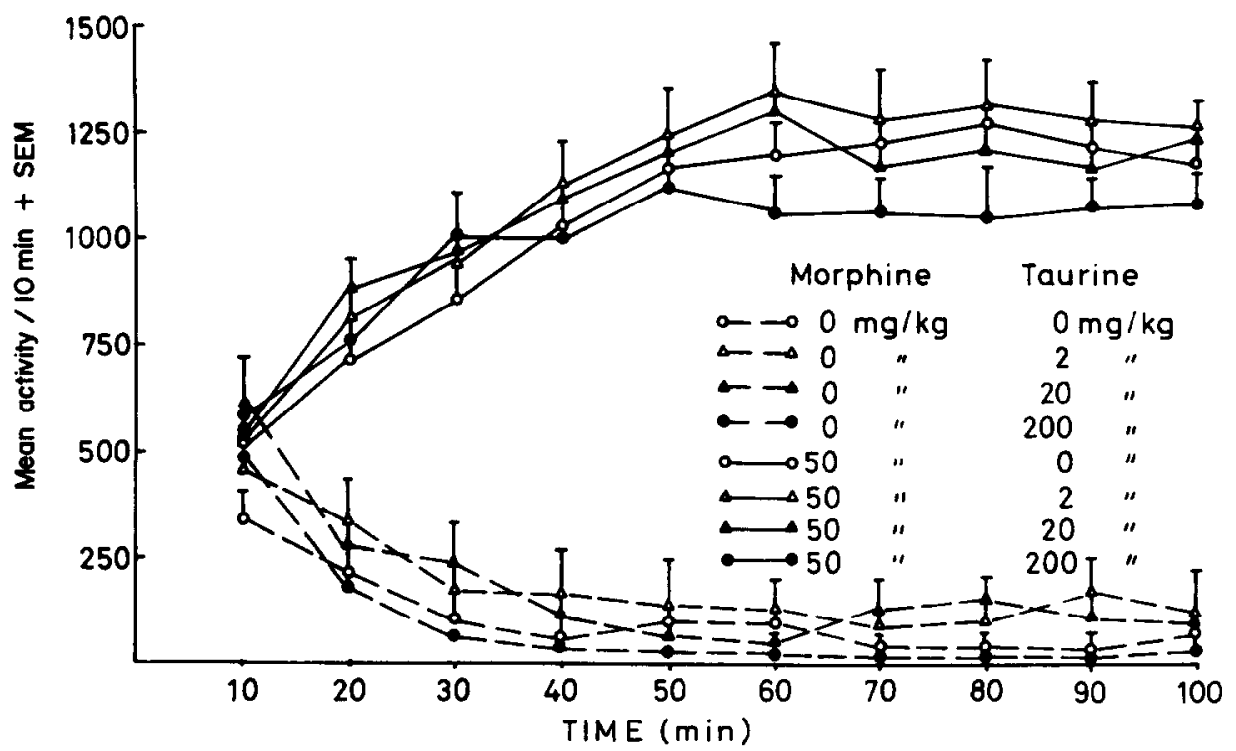

Fig. 3. Interactions between taurine and morphine. Motor activity is displayed as means and standard errors based upon 9 determinations per data point. Broken lines represent groups not receiving morphine while solid lines are morphine injected $(50 \mathrm{mg} / \mathrm{kg}$, i.p.); open circles and triangles, and solid triangles and circles represent $0,2,20$ and $200 \mathrm{mg} / \mathrm{kg}$ of taurine respectively, injected 30 min prior to morphine. Extensive $(5 \mathrm{hr})$ habituation preceded testing. Recording was based upon a remote sensing device as described in the text. 


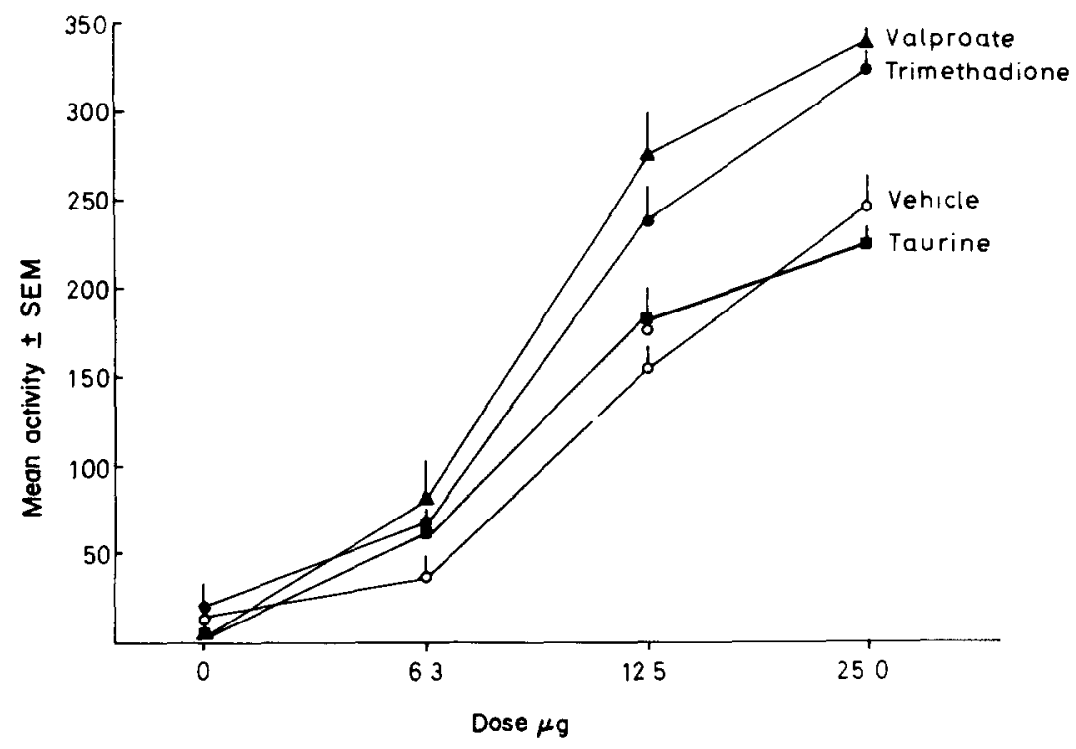

Fig. 4. Summary Figure displaying dose-response relationships for an enkephalin analog ( $D$-ala ${ }^{2}$-leuenkephalinamide) after vehicle or intermediate values of trimethadione $(50 \mathrm{mg} / \mathrm{kg})$, sodium valproate $(12.5 \mathrm{mg} / \mathrm{kg})$ and taurine $(20 \mathrm{mg} / \mathrm{kg})$ injected in doses based upon Figures $1-3$. Mean motor activity per 100 min session plus standard errors are displayed. Apparatus is described in Figures 1-3 and text.

the mouse. In comparison with vehicle, morphine was behaviorally facilitatory (Figs $1,2,3$-respective $F$ 's 12.9. 15.7. 22.0. $P<0.0001$. d.f. $=1.48 ; 1.48 ; 1.69$ ). While none of the anticonvulsants had any facilitatory effect upon normal activity (in all cases $F \leqslant 1$ ), two (trimethadione and sodium valproate) specifically facilitated morphine activity $(F$ 's for interactions $=11.1,8.3 ;$ d.f. $=2,48 ; P<0.0001)$. This interaction was not present for taurine $(F=1.3$; d.f. $=3.64: P=0.3$ ). Although reliable main effects for time were not present $(F$ 's $\leqslant 1.5$, d.f. $=9,432$; 9,$432 ; 9,655, P=0.1$ ), reliable effects of drug (i.e. morphine) by time (respective $F^{\prime} s=4.7,4.2,3.8$, d.f. $=9.432 ; 9.432 ; 9,655, P<0.01)$ and three way interactions $[F$ 's $=7.9,6.2,1.0 ;$ d.f. $=18,432 ; 18.432$; 24.655: $P<0.01$ except taurine (NS) were found. Effects of anticonvulsants by time were not significant beyond chance $(F$ 's $<1)$ except for taurine $(F=2.1$; d.f. $=24,655 ; P<0.001$ ).

Central injections of the enkephalin analog produced a graded behavioral response and both trimethadione and valproic acid shifted the enkephalin analog behavioral response curve to the left (Fig. 4). Taurine lacked this effect (Fig. 4). The behavioral fundings are consistent both with the previous findings and the results of the last experiment. The main effect for the enkephalin analog was statistically reliable beyond chance $(F=13.1$; d.f. $=3.64 ; P<0.001)$ and both valproic acid and trimethadione significantly increased the level of opioid activity, shifting the doseresponse curve $(F$ 's $=9.9,8.9$ respectively; d.f. $=9.64$; $P<0.001$; for taurine, $F=1.8, P \sim 0.3$ ). Time was not a main factor (all $F$ 's $<1.2$; d.f. $=8,597$ ), although time did interact with enkephalin $(F=18.0$; d.f. $=24,597)$ and, in addition, a three-way interaction was present $(F=3.1$ : d.f. $=72.597)$.

\section{DISCUSSION}

The present findings extend previous findings by Katz and Schmaltz (1979) to two novel but clinically used anticonvulsant drugs (trimethadione and sodium valproate). The effect was not present for taurine, at least within the present dose range: this may be explained by a number of unique postulated modes of action of the latter. Unlike other anticonvulsants, taurine is not an effective treatment for kindled seizures which may represent an experimental analog of epilepsy (Wada, Osawa, Wake and Corcoran, 1975). Furthermore, in yet other preclinical models, taurine was shown to have a proconvulsant effect (Frigyesi and Lombardini. 1979). Although these findings do not rule out positive clinical findings, especially given procedural variations such as chronic administration, they do offer potential explanations of the discrepant actions of taurine in the present model.

The findings with the analog confirm and extend previous studies on opiate-anticonvulsant interactions. As with morphine, an effect was seen for two compounds, valproic acid and trimethadione, but not for a third, taurine. The reasons for an absence of effect with the latter compound have already been suggested. The present findings suggest that the effects of anticonvulsants are not upon drug disposition, nor restricted to a single opiate.

The findings, taken as a whole, suggest that actions of opiates which are altered by anticonvulsant treatment are behaviorally significant. The facilitation effects are not found in certain classes of therapeutically effective compounds however, at least in the present testing circumstances. Thus, it may be concluded that anticonvulant facilitation of opiate effects is general, but apparently not universal. 
Acknowledgements-The technical assistance of Giulio Baldrighi and $R$. Chudler, the statistical assistance of R. C. Shea and the editorial assistance of Abe Feingold are acknowledged with gratitude. Dr Katz is a Sloan Research Fellow in Neuroscience.

\section{REFERENCES}

Cookson. S. L. and Mann, J. D. (1978). Reversal and prevention acute morphine induced catalepsy in naive rats. Soc. Neurosci. (abstr.), 4: 488.

Dixon, W. J. and Massey, F. J. (1969). Introduction to Statistical Analysis. McGraw Hill, New York.

Frigyesi, T. L. and Lombardini, J. B. (1979). Augmentation of thalamo-motor cortico-cerebellar epileptogenesis by taurine and its antagonism by diphenylhydantoin. Life Sci. 24: $1251-1260$
Katz, R. J. and Schmaltz. K. (1979). Facilitation of opiate and enkephalin induced motor activity in the mouse by phenytoin sodium and carbamazepine Psychopharmaco$\operatorname{logy}$ 65: $65-68$.

Katz, R. J., Carroll, B. J. and Baldright, G. (1978). Behavioral activation by enkephalins in mice. Pharmac. Biochem. Behav, 8: 493-496.

Tortella, F. C.. Moreton. J. E and Khazan N. (1978). Electroencephalographic and behavioral effects of $\mathrm{D}$-ala ${ }^{2}-$ methioninte-enkephalinamide and morphine in the rat. $J$. Pharmac. exp. Ther. 206: 636-642.

Urca, G., Frenk, H., Liebeskind, J. C. and Taylor, A. N. (1977) Morphine and enkephalin: analgesic and epileptic properties. Science 197: 83-86.

Wada. J. A., Osawa. T. Wake, A. and Corcoran, M. E. (1975). Effects of taurine on kindled amygdaloid seizures in rats, cats and photosensitive baboons. Epilepsia 16: $229-234$. 